Please quote as: Schöbel, S.; Ernst, S. -J.; Söllner, M. \& Leimeister, J. M. (2017): More than the Sum of its Parts - Towards Identifying Preferred Game Design Element Combinations in Learning Management Systems. In: International Conference on Information Systems (ICIS). Seoul, South Korea. 


\title{
More than the Sum of its Parts - Towards Identifying Preferred Game Design Element Combinations in Learning Management Systems
}

Short Paper

\author{
Sofia Schöbel \\ University of Kassel \\ Information Systems \\ Pfannkuchstraße 1, 34121 Kassel, \\ Germany \\ sofia.schoebel@uni-kassel.de
}

\author{
Sissy-Josefina Ernst \\ University of Kassel \\ Information Systems \\ Pfannkuchstraße 1, 34121 Kassel, \\ Germany \\ sissy.ernst@uni-kassel.de
}

\author{
Matthias Söllner \\ University of Kassel/University of St. Gallen \\ Information Systems/Institute of Information Management \\ Pfannkuchstraße 1, 34121 Kassel, Germany / Müller-Friedbergstraße 8, \\ 9000 St. Gallen, Switzerland \\ [soellner,leimeister]@uni-kassel.de/[matthias.soellner, \\ janmarco.leimeister]@unisg.ch
}

\begin{abstract}
Gamification refers to the use and combination of game design elements in a nonentertainment-based context. Despite the preliminary success of gamification, nowadays the concept faces some criticism. Most gamification projects do not consider context characteristics and implement elements without considering user needs. This can be observed in the inconsistent combination of elements and the varying results of research studies. Consequently, we aim to identify which element combinations users of learning management systems prefer. To achieve our goal, we plan to use a conjoint analysis which allows us to evaluate different element combinations. Based on our results, we expect to better understand the meaning of elements, and therefore, how gamification motivates users. As a practical contribution, we provide insights on how to combine elements against the backdrop of user preferences and context characteristics. Our theoretical contribution is to be able to explain users' motivational structures by analyzing specific elements and combinations.
\end{abstract}

Keywords: Gamification, Game Design Elements User Preferences, Conjoint Analysis, Element Combinations, Learning

\section{Introduction}

Learning Management Systems (LMSs) are one example of information systems (Alavi and Leidner 2001; Sims 2003) that are used in organizations and universities for the training of employees and students (Urh et al. 2015). Besides the term LMSs, such systems are often referred to as e-learning, technology-mediated 
learning, or virtual learning. However, because of a lack of user motivation, LMSs have shown a high dropout rate (Bedwell et al. 2012; Demetrovics et al. 2011; Santhanam et al. 2016; Shang and Lin 2013). Hence, gamification has become a popular method to motivate users towards a more regular system use (Bui and Veit 2015). This method can be defined as the use and combination of computer games' mechanics (so called game design elements) within a non-entertainment-based context (Deterding et al. 2011). Although the initial idea of integrating game design elements in order to motivate people to use an information system sounds promising, the current efforts to integrate the concept of gamification are criticized in research as well as in practice (Fogel 2015; Santhanam et al. 2016). Besides some criticism about the overall gamification concept, most projects often fail due to the missing consideration of the needs and preferences of system users (de-Marcos et al. 2014, Fleming 2014; Fogel 2015). More precisely, Fleming (2014) and deMarcos et al. (2014) indicate that current gamification concepts are designed as one-size-fits-all solutions without knowing which game design elements users really want to have implemented. In this regard, Schlagenhaufer and Amberg (2015) point out that only few empirical studies include user preferences when aiming to develop a gamification approach.

The missing consideration of user preferences in gamification concepts can be well observed in the different approaches and results of previous research studies. Referring to this, some research studies obtain different results even if they use nearly the same combination of game design elements within the same context. Seixas et al. (2016) and Hamari et al. (2014), for example, combined points, badges, levels, and goals. Both research studies proved positive motivating effects. Hanus and Fox (2015) used the same elements but instead of levels and goals, they used a competitive leaderboard. Contrary to the results of Seixas et al. (2016) and Hamari et al. (2013), the motivational effects were negative. Insights regarding current research examining game design elements draw a colorful picture showing a broad palette of game design elements, which appear in various forms and combinations and with different results. Overall, the results indicate that game design elements are oftentimes merely chosen and integrated, however the preliminary considerations that lead to these specific choices of game design are not explained and not adapted to the needs of users, thus, they are not comprehensible in many cases. Based on this proposition, the goal of our short paper is twofold. First, we want to analyze how game design elements can be combined. These combinations are useful for our second aim: providing insights on how we can identify which game design element combinations users of LMSs prefer. Overall, our short paper is based on the following two research questions:

\section{$R Q$ 1: How can game design elements be combined? \\ RQ2: How can user preferred game design element combinations be identified?}

To achieve our research goals, we start by identifying categories for game design elements. These categories are necessary for conducting a conjoint analysis. A conjoint analysis can be used to determine how individuals value different attributes such as game design elements that constitute of an individual product or, in our case, a combination of game design elements (Hair et al. 2010). After finishing our research, we will be able to provide implications about the use and combination of specific game design elements, as they serve as a starting point for the examination of the role and the meaning of user preferences in gamification. Concerning our overall research aim, we can give theoretical implications on the role and meaning of user preferences within the construction of gamification approaches. More precisely, besides drawing conclusions about the most preferred game design element combinations, we can also deliver insights about which individual element users prefer and which they dislike. We will also be able to analyze which game design element combination specific groups of users prefer. Hence, we can identify differences in game design element combinations, which in turn enables us to explain the relation between the motivation of users, specific elements and element combinations. Thus, we also can better explain how motivation in learning can arise and what teachers and lecturers could do to motivate their students. Practical implications can be provided on how to integrate game design element combinations into LMSs.

The short paper is structured as follows: After having explained the motivation of our short paper, we continue in the next section with a definition of gamification and specify the term LMS. Afterwards, we will describe the method we intent to use for our planned analysis and we will describe our planned data analysis. The paper closes with a description of the next steps and a summary of the theoretical and practical contributions. 


\section{Theoretical Background}

In the following section, we are going to define the important terms of our short paper. Besides defining the term of gamification, we are going to present the results of a literature review. The review was conducted to understand how previous studies combined game design elements. Furthermore, we wanted to explore in how far previous research studies considered the interests and needs of their target groups. Finally, we will present a definition of the term LMS and describe how gamification relates to learning.

\section{Gamification}

Gamification has its origin in the use of games in daily life (Hsu-Hwa et al. 2013). People like to play games during their spare time, at home, or on their way to work (Attali and Areli-Attali 2015). The term gamification originated in the digital media industry. The most prominent definition of gamification was developed by Deterding et al. (2011). They define gamification as an informal umbrella term for the use of video game elements in non-gaming systems to improve user experience and engagement. Referring to this, gamification can also be defined as the use and combination of game design elements in nonentertainment-based contexts to improve the motivation and engagement of users to use an information system more regularly (Deterding et al. 2011). Using the concept of gamification involves the use of game design elements (Blohm and Leimeister 2013). More precisely, game design elements can be separated into game mechanics, game dynamics, and game aesthetics (Hunicke et al. 2004). Game mechanics such as points (Burke and Hiltbrand 2011) are the functioning components that allow a designer ultimate control over the levels of a game (Zichermann and Cunningham 2011). Dynamics on the other hand are described as the user's interaction with these mechanics (Zichermann and Cunningham 2011). Aesthetics describe the emotional response evoked in individuals (Hunicke et al. 2004). Some specific mechanics such as a leaderboard always refer to the dynamics of competition because they allow users to compare their own results with the results of other users (Christy and Fox 2014).

Since several research studies demand the consideration of contextual aspects when developing a gamification approach (Hanus and Fox 2015), our research focuses on the field of learning. Gamification in learning is used to ensure that users of LMSs pay attention and engage with learning materials (Hanus and Fox 2015). More precisely, motivation represents a very important outcome of gamification models as it differentiates gamification from tedious tasks and increases user activity (Deterding et al. 2011). What kind of motivational orientation is activated by the gamification model depends on the individual and on the game design elements that are used (Schöbel et al. 2016). Referring to users' activity, motives are very important (Leimeister et al. 2009). Motives are an individual's psychological disposition that is understood as a relatively stable set developed during an individual's socialization process. In a specific context, an analogous motive will be activated and subsequently causes a particular behavior (Leimeister et al. 2009). Activation means that an individual reacts to a perceived inborn stimulus or an external incentive. Referring to gamification, game design elements can be seen as external incentives who activate, for example, a more regular usage of a learning management system (Agarwal and Karahanna 2000). However, to achieve positive effects on the motivation and usage behavior of individuals, most studies use one-size-fits-all approaches that do not consider what users seriously need and want (Santhanam et al. 2016). Especially Mekler et al. (2017) explain that more research should investigate the role of situational and contextual aspects, which can partially determine the success or failure of a gamification approach. Referring to motivation in learning, intrinsic motivation is understood as the desire to learn; it originates from within the student (Deci et al. 2001). Learners are extrinsically motivated to perform, whenever their motivation for a certain behavior is triggered by an outside force, such as rewards (Deci et al. 2001; Hanus and Fox 2015).

To gain first insights regarding the game design element combinations that are used in gamification approaches and regarding the way user preferences were considered, we conducted a systematic literature review (Vom Brocke et al. 2015; Webster and Watson 2002). Relevant literature was identified via a systematic database search including several databases. For the coverage of a broad set of publications, the keywords "gamification", "learning", and "game design elements" were used. A paper was only selected if it focused on either gamification in terms of definition or game design or on game design elements in general. Furthermore, we excluded papers such as literature reviews or qualitative studies and concentrated on empirical research studies that used quantitative analyses to evaluate gamification approaches and to 
interpret their outcomes. Additionally, in this stage of the process a lot of papers were identified through cross-referencing. In total, 58 papers were of relevance to our research. To conduct a conjoint analysis, we had to identify all existing elements that are being used for gamifying learning management systems at first. Referring to this, we could find a study from Thiebes et al. (2014), who also conducted a literature review. They summarized all game design elements that had been used in previous studies by focusing on the workplace. The authors present a list of 31 different game design elements. With regard to the game design elements that had been used in the studies, in our literature review, we identified that all game design elements presented by Thiebes et al. (2014) are used in the area of learning as well. Focusing on the results of our literature review, we can say that a large portion of studies addressed the competitive game dynamics by integrating a leaderboard that allows the comparison of own results with the results of others (Alcivar and Abad 2016; Cheng et al. 2015; Latulipe et al. 2015). Additionally, several studies also refer to the dynamics of cooperation by integrating mechanics that reward users for working together with others or helping others (Boticki et al. 2015; Fernandes et al. 2012; Kuo and Chuang 2016). Referring to the game mechanics, most studies used goals, points, and leaderboards. Furthermore, points are often used as a basic element for other elements such as levels (Alcivar and Abad 2016), leaderboards (Christy and Fox 2014), or progress bars (de-Marcos et al. 2014). The amount of combined mechanics varies between two (Hew et al., 2016) and nine gamification mechanics (Domínguez et al. 2013). The partially high number of mechanics combined is surprising, as some research studies point out that implementing too many mechanics in an LMS can have contrary effects on the motivation to use an LMS (Hanus and Fox 2015). Concerning mechanics, most studies combined points, goals, badges, leaderboards and feedback (Denny 2013; Eckardt et al. 2015; Faghihi et al. 2014; McDaniel et al. 2012).

By looking at which game design elements previous studies use and how they combine the elements, we found out that each study has a different understanding of the meaning of specific elements. Due to this, it gets more difficult to adapt gamification approaches to the needs of users. Furthermore, the combination gets more difficult, because a unfavorable combination could possibly change the meaning and relevance for the intended target group (Hanus and Fox 2015). Some studies apply just one distinctive game design element such as badges without specifying their meaning (Boticki et al. 2015; Denny 2013). Furthermore, we can say that none of the research studies considered the needs and preferences of their target groups. Furthermore, all studies combine the game design elements without considering whether game mechanics such as leaderboards, which address competitive dynamics, are suitable for the target group or not. The research studies deliver different results regarding the effects and outcomes of the use of gamification. This might be the result of the different meanings of specific elements and the missing consideration of the user's needs. Li et al. (2012), for example, implement and analyze the mechanics feedback, points, bonus, levels, goals, and time pressure. On the other hand, Attali and Arieli-Attali (2015) combine the mechanics feedback, points, bonus, leaderboard, and time pressure. While Li et al. (2012) can determine positive effects concerning engagement and learning outcomes, Attali and Arieli-Attali (2015) have mixed results regarding the success of gamification. Changing the element combination by replacing the levels with a leaderboard puts the approach in a competitive surrounding that possibly explains the different results. Shute et al. (2015) and Hamari (2015) integrated the four mechanics points, badges, level, and goals into their research study. The evaluations of both studies deliver positive effects on the motivation to learn and the learning outcomes. Hew et al. (2016) use the same game mechanics but they replace levels and goals by the mechanics bonus and leaderboard. Unlike Shute et al. (2015) and Hamari et al. (2015), the authors Hew et al. (2016) were not able to prove positive effects for their learning outcomes. Although the authors used a cooperative leaderboard instead of a competitive leaderboard, they could not achieve positive effects. The literature review indicates that there are no approaches for considering the needs and interests of the intended target group. This might be one explanation for the different results. These results indicate that more research needs to focus on the analysis and combination of game design elements for a specific target group.

\section{Gamification in Learning Management Systems}

In our research, we will focus on LMS. Such systems often have a utilitarian purpose and are used on a voluntary basis in several areas of application such as companies or universities (Hess et al. 2014). More precisely, a LMS can be defined as "an environment in which users' interactions with learning materials, peers, and/or instructors are mediated through technologies" (Alavi and Leidner 2001; Sims 2003). Overall, LMSs are used to support students or employees to improve their learning and they enable learning 
from anywhere and at any time (Urh et al. 2015). Furthermore, gamification has proven to be an effective concept motivating LMS users towards a more regular system use (Scheiner and Witt 2013). More precisely, gamification in learning has become more important because of the increasing number of interdisciplinary programs broadening the field of application for gamification (Urh et al. 2015). Therefore, gamified learning as well as LMSs have two purposes (Ibánez et al. 2014). The first is to encourage a desired learning behavior. The second is to engage users in learning by including learning materials such as tutorials or digital documents. Referring to this, engagement has been proven to be positively correlated with the outcome measures of user success, such as user satisfaction and academic achievements (Ibánez et al. 2014). Accordingly, gamification increases the motivation of users to learn by providing different game design elements, encouraging exchange between students, and, thus, by making an activity or task more fun and engaging. In the following, we will describe our research method for the analysis of different game design element combinations in LMSs.

\section{Methodology and Status Quo}

To analyze which game design element combinations users of LMSs prefer, we decided to conduct a conjoint analysis. Referring to this, two steps are necessary. They can be seen in Figure 1.

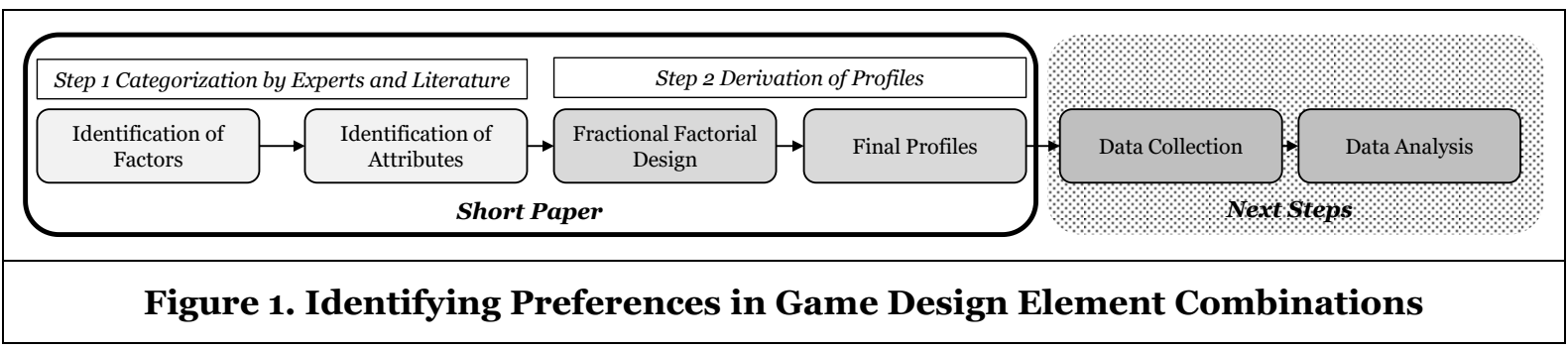

In our short paper, we will merely describe step 1 and 2 . The data collection is still in progress. In line with the preparation for a data analysis, in a first step, we asked experts in an iterative process to categorize the identified game design elements and to define these categorizations. Then, we compared their results to the results of our literature review. In a second step, we used the identified categories for deriving profiles (game design element combinations). This is necessary for conducting a conjoint analysis, which itself consists of two subtasks: the identification of fractional factorial design and an online survey with the aim to finally identify the game design element combinations users of LMSs prefer the most.

\section{Conjoint Analysis}

By using a conjoint analysis, we can analyze game design elements on an individual as well as on an aggregated level. The conjoint analysis is a widespread and well-known approach in research and practice. Typically, the conjoint analysis is used in the field of marketing research to evaluate design and configuration options based on user preferences (Green and Srinivasan 1990). Besides the traditional conjoint analysis, the choice-based analysis, as well as the adaptive conjoint analysis are often used (Orme 2009). When using the traditional conjoint analysis, a ranking or rating procedure can be used. The conjoint analysis is a technique to understand how respondents develop preferences for specific objects (Hair et al. 2010). Objects can be products, services, or ideas. Each object has different attributes. Within a conjoint analysis different combinations of attributes are presented to respondents. To conduct a conjoint analysis certain steps are necessary. First, factors and attributes must be identified. A factor consists of different attributes manipulated by the researcher (Hair et al. 2010). Attributes on the other side describe a factor. Typically, a factor never exceeds four or five attributes. In a second step, profiles are identified. Profiles are constructed by combining attributes from each and every factor (Hair et al. 2010). For defining profiles two common methods can be used. One method for defining profiles is the full factorial design which creates every possible combination out of all attributes (Hair et al. 2010; Leigh et al. 1984). If there are, for example, two factors with three attributes per factor a full factorial design would create (2x3) 6 profiles. Most of the time, more factors and attributes are used in research studies. To analyze greater amounts of factors and attributes the method of a fractional factorial design can be used (Hair et al. 2010; Leigh et al. 1984). More precisely, by using a fractional design only a subset of possible profiles will be presented to individuals. With this method, the number of profiles is reduced, however, orthogonality among the attributes is still 
maintained. The reduced set of profiles is presented and evaluated by individuals belonging to the target group. Afterwards, the gained data is analyzed. In the first step, we will describe the identification of factors and their attributes. For our research, we decided to use a traditional conjoint analysis with a ranking procedure. We decided to use this kind of conjoint analysis because other kinds suffer from a lack of ties (Cohen 2003). By using a ranking procedure, we are able to construct sub-categories. Hence, before making a ranking, respondents can decide about the general preference of specific combinations by categorizing them, for instance, in two categories - "preferred" and "not preferred". By building sub categories, respondents only have to rank a limited amount of combinations at once (Hair et al. 2010). This makes the results more valuable. On the other hand, when using a rating procedure, participants are allowed to rate every choice option equally high. This, of course, would not lead to any usable results as no preference differences are reflected by the ratings (Matzner et al. 2015).

\section{Step 1: Categorization of Elements}

To analyze game design element combinations with a conjoint analysis, factors and attributes should be identified. So far, there is a lack of consistent and conclusive categories of game design elements (Seaborn and Fels 2015). The most common and well known framework was developed by Hunicke et al. (2004). They define the so-called MDA framework which includes mechanics, dynamics, and aesthetics. Deterding et al. (2011) on the other hand, define mechanics, design principles, conceptual models, and design methods within their framework. However, for conducting a conjoint analysis and for getting meaningful results, a more detailed categorization is necessary. Hence, we decided to involve gamification experts. We asked six gamification experts to categorize game design elements. Referring to the results of our literature review and the game design element list from Thiebes et al. (2014), 31 different game design mechanics which do not follow a logical categorization order exist. We presented a list and a definition of each element to three of our experts. In a first step, the three experts were asked to choose the elements which cannot be used for the construction of a gamification approach, such as motives or dynamics. In the next step, we asked the experts to categorize the remaining elements. The experts had to define each category and to assign each of the remaining game design elements to one category. For categorizing the elements, the three experts had the instruction to summarize similar elements. To confirm the categories and assigned elements, we presented the definitions of each category to the remaining three experts. These experts were not involved during the first two steps. However, they had to repeat the assignment of the elements according to the definitions of the other three experts. Referring to the conjoint analysis, the category names are the factors. The assigned game design elements are the attributes. The results can be seen in Figure 2.

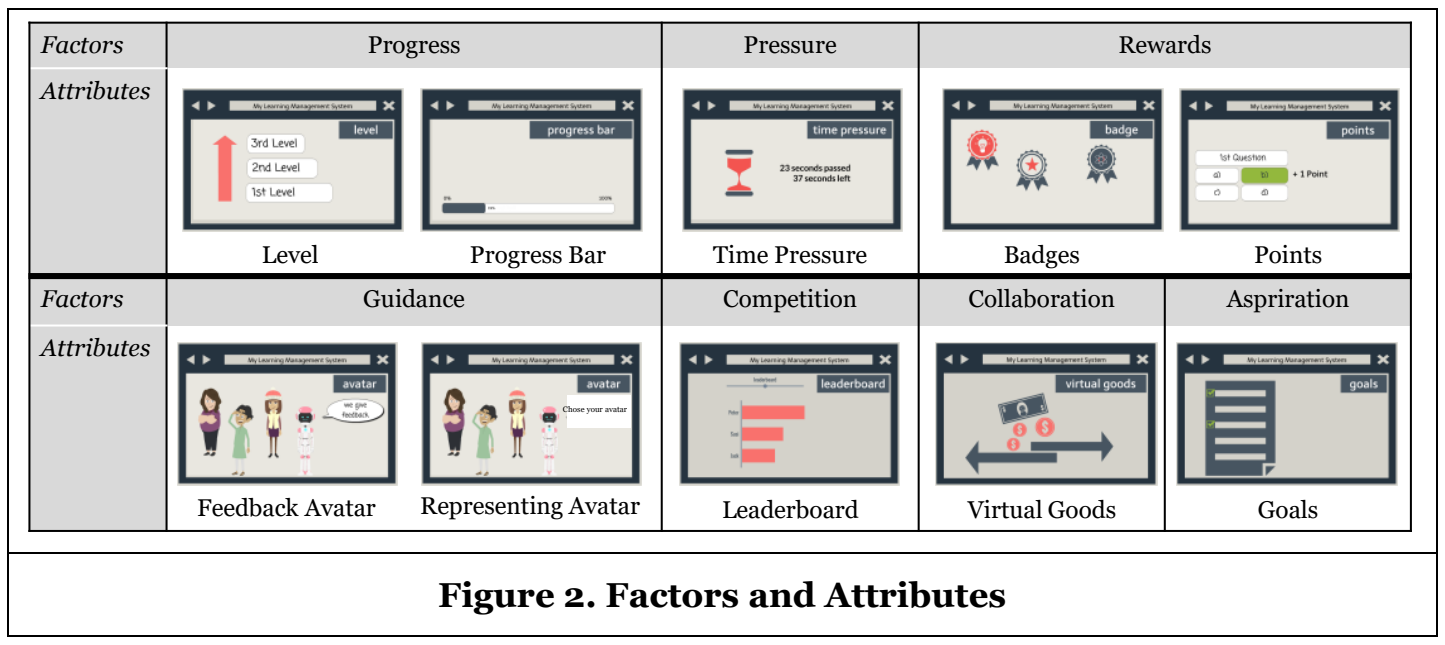

The factor progress integrates elements that visualize the progress of an individual during the system use and especially during the learning progress. As reported by our experts the first element for the factor of progress is a level. A level indicates the proficiency of a user in the overall progress of system activities (Gnauk et al. 2012). The lowest level is the first and a user can rise to a higher level by successfully finishing tasks or activities in a system. The levels build on one another and the upper level can only be reached by successfully finishing the previous level. Another progress element is a progress bar (Huotari and Hamari 2012). Again, a progress bar visualizes the user's overall progress. However, a progress bar reports the 
progress in percent, reaching from $0 \%$ (no progress) to 100\% (high progress). Compared to a level, a progress bar has no stages which need to be completed for rising to the next stage. In comparison to the results of our literature review, element levels and progress bars are used for documenting the behavior and the progress of learners (Bui and Veit 2015; de-Marcos et al. 2014). In all studies using levels or progress bars, both elements represent the overall success of learners during the system use. Hence, the results of our literature review correspond to the categorization recommendation of our experts. Our experts named the next factor pressure. This factor includes elements that influence a user's behavior not by a reward but by pressure or punishment whenever a task is not completed successfully (Liu et al. 2011). Referring to our experts, the element time pressure belongs to the factor. By using time pressure in activities or tasks, a user is either forced to finish a task as fast as he can or he has a limited time window for finishing a task or activity (Li et al. 2012). Referring to our literature review, time pressure is the only element that exerts pressure on learners by including a counter or an hour glass while working on knowledge tests. This motivates learners to finish a test as fast as possible (Faghihi et al. 2014; Passos et al. 2011). The results of our review point out that there are no similar elements which could be included as attributes to the category of pressure. Hence, we agree with the results of our experts.

The next factor was named rewards. A user receives a reward for successfully completing a task or activity. Unlike points, badges are visual icons a user receives as a reward (Hamari 2013). Points are numeric values added to an overall point score (Burke and Hiltbrand 2011). Referring to our literature review, both elements have one common characteristic; they can be collected and are part of an overall scoring system (Fernandes et al. 2012; Hew et al. 2016; Su and Cheng 2015). Therefore, we decided to use the recommended attributes from our experts for the factor rewards. The next factor is guidance. Most research studies refer to feedback as a game design element (Passos et al. 2011). Feedback is usually used to keep a user aware of his progress or failure during the system use. Our experts specified that an avatar could be used to constantly provide a user with feedback. Hence, the element avatar belongs to the factor guidance. An avatar is the representation of the self (Thiebes et al. 2014). Furthermore, an avatar accompanies the user during the system use and gives feedback to a user (Bjork and Holopainen 2004). Referring to our literature review and the presented definitions, we adapted the results of our experts by integrating two kinds of avatars (Alcivar and Abad 2016; Bedwell et al. 2012; Christy and Fox 2014; Perry 2015). Feedback avatars focus on providing feedback to the users. Representation avatars are used to represent users. The next factor is competition. Competition enables users to challenge each other (Thiebes et al. 2014). According to our experts, a leaderboard can be used to establish competition between users. A leaderboard is a ranking visible to all users. It represents a user's progress compared to others (Bunchball 2010; Christy and Fox 2014). All studies of our literature review use a leaderboard to increase competition between learners (Attali and Areli-Attali 2015; Davis and Singh 2015; Denny 2013).

The second last factor was named collaboration and includes elements that are given to users for successfully working with others. Based on the meaning of our experts, virtual goods can be used to strengthen collaboration between individuals. Virtual goods are non-physical, intangible objects which can be handled or traded with others, such as coins (Thiebes et al. 2014). Referring to our experts, especially handling and trading seems to be important for collaboration. This corresponds to how virtual goods have been used in previous research studies (Perry 2015; Simoes et al. 2013). The last factor is aspiration. Aspiration refers to elements that challenge users to continue working with the LMS or stimulate users to strive for something. Our experts chose the attribute goals for this category. Goals underline an activity or task that is considered a challenge for the user (Passos et al. 2011). In all research studies we identified in our literature review, goals are used for challenging users, e.g. "finish the last section of the lection within the next two days" or "find the right answer for at least 50\% of the questions" (Bui and Veit 2015; Burgers et al. 2015; Domínguez et al. 2013). Apart from the named attributes, we also considered that some elements could be left out in a combination. If a participant is not interested in competition, a leaderboard could be left out. In the following, we will describe the process of identifying game design element combinations.

\section{Step 2: Derivation of Profiles}

After specifying the factors and attributes, we could identify the profiles. In our case, a profile is a combination of game design elements. As mentioned above, there are two methods for creating the profiles

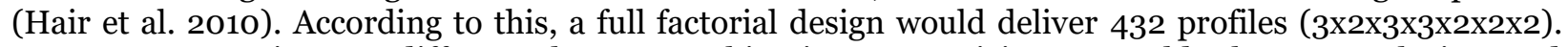
However, presenting 432 different element combinations to participants would take too much time and strain the participants' concentration. That is why we used the fractional factorial design. By using a 
fractional design, only a subset of possible profiles will be presented to the respondents. Although the number of profiles is reduced, the orthogonality among the attributes is still maintained (Hair et al. 2010). Therefore, by using the software program $\mathrm{R}$, we were able to identify the fractional factorial design consisting of 18 profiles (Aizaki 2012; Aizaki and Nishimura 2008). The profiles are depicted in Figure 3.

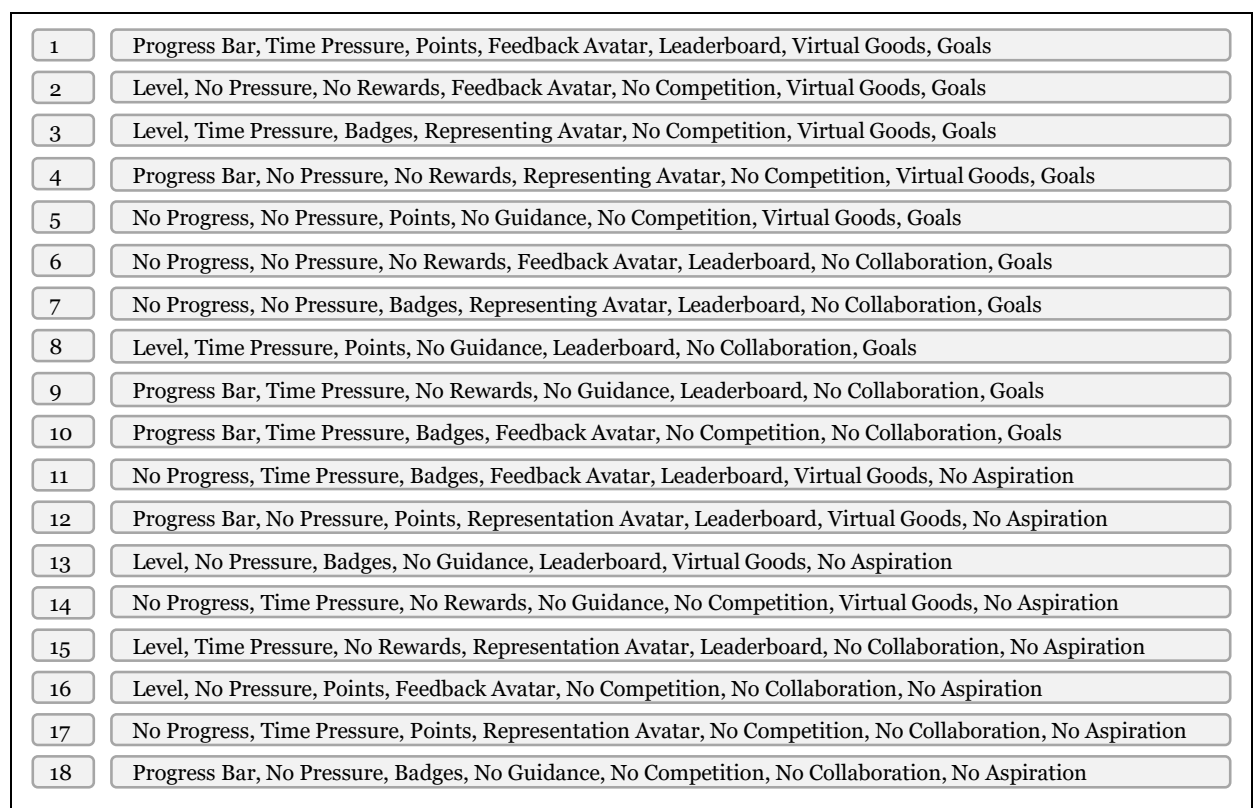

Figure 3. Game Design Element Combinations for Online Survey

The factor pressure for example has two attributes. The first attribute time pressure is used in nine of the profiles, whereby the other nine profiles have no pressure as an attribute. Although it is a reduced number of profiles, all attributes are still orthogonal, thus, we can guarantee the validity and reliability of the results.

\section{Next Steps, Expected Contributions, and Future Research}

The goal of our short paper was to identify different game design element combinations as well as a possibility for evaluating which combinations users of LMSs prefer. Therefore, we could work on providing a categorization of game design elements, which can then be used for conducting a conjoint analysis. In the following, we describe our planned data collection and analysis as well as the contributions and ideas for future research.

\section{Planned Data Collection and Expected Contributions}

In a next step, we plan to conduct the conjoint analysis. There are two different kinds to conduct conjoint analysis: computer-based or paper-based (Eggers and Sattler 2009; McFadden 1973). When conducting a computer-based analysis, an online survey is necessary. A paper-based conjoint analysis can be conducted by using a paper-based survey, or by interviews. We decided to use a computer-based analysis, because it is easier to obtain a higher sample size (Eggers and Sattler 2009). According to this, we are going to divide our survey into four different parts. The first part will start with a description of the different game design elements. Therefore, we plan to integrate a description of each element as well as a corresponding video. The video will explain and visualize how the different game design elements work. Before conducting the conjoint task, we will integrate control questions to make sure that our participants know the presented game-design elements. The second part of our survey will be the conjoint task. Therefore, we will divide the task into three sub-tasks. In a first step, our participants will be asked to divide all combinations into three sub categories: very important, moderate, not at all important. Afterwards, they will be asked to rank the combinations for each category. Hence, the participants do not have to focus on all combinations at a time. In the third part, we will integrate different scales to evaluate the motivational structures of each participant (Barryl et al. 2014; Burgers et al. 2015; Filsecker and Hickey 2014), which will be helpful to explain which 
game design element combinations participants prefer. More precisely, we will evaluate whether users are mastery or performance-oriented learners (Hakulinen and Auvinen 2014; Zusho et al. 2005). Performanceoriented learners are for example motivated whenever they can compare their results with those of others. Hence, they might be more interested in a game design element combination that involves a leaderboard. Mastery learners on the other hand are more interested in their own progress. Hence, they would probably not be interested in a gamification bundle that involves competitive game design elements. Furthermore, we will include scales for measuring the respondents intrinsic and extrinsic motivation (Amabile et al. 1994). Finally, we will evaluate demographic data such as age and gender (Venkatesh and Morris 2000). By evaluating this data, we will be able to make further group analyses. Hence, we can calculate, for example, a cluster analysis (Hair et al. 2010). That enables us to identify game design element combinations for specific groups of users. To assess the quality of our analysis, we plan to conduct a pre-test. In a first step, we intend to ask researchers for testing our survey aiming at the question whether the survey is accurate and the integrated questions and element explanations are understandable.

Our research will provide theoretical and practical contributions. First, we can explain which game design element bundles users prefer. According to Seaborn and Fels (2015), more research should focus on determining the usefulness of particular game design elements. Besides drawing conclusions about the most preferred game design element combinations, we can also deliver insight about which individual element users prefer and which one they dislike. Furthermore, by evaluating and analyzing the results for different kinds of user groups such as mastery or performance-orientated learners, we can identify differences in game design element combinations, that in turn enables us to explain the relation between the motivation of users, specific elements, and element combinations. Thus, we can also better explain how motivation in learning can arise and what teachers and lecturers could do to motivate their students. Finally, according to Santhanam et al. (2016), more research should focus on individual instead of one-sizefits-all approaches. Thus, after implementing game design element combinations in a LMS, we can get a better understanding of the role and meaning of user preferences. Furthermore, by identifying and considering game design element combinations for a specific group of users, we can better isolate and explain the effects gamification has on users. Additionally, we can provide practical contributions to system developers by formulating design guidelines that help to explain how to combine game design elements and make them appealing to a specific group of users in a certain context.

\section{Limitations and Future Research}

Our study is not without limitations, which provide implications for future research. Relating to the survey participants, we will focus on university students. Hence, further analysis should consider other subject groups such as employees who use LMS within their company. Additionally, we plan to use a traditional conjoint analysis. Future research could use, for example, other conjoint methods such as a choice-based approach, because listing attributes in a ranking procedure is somehow unnatural for individuals who are no gamification experts (Baumgartner and Steiner 2007). Finally, we plan to conduct an online survey for analyzing which game design element combinations users prefer. Hence, it is necessary to implement game design elements into a LMS for evaluating the identified gamification bundles and their long-term effects on the motivation and usage behavior of users. Thus, our results could be used for an experiment. The most and least preferred game design element combinations could be implemented into a LMS. By implementing such combinations in a LMS, their effects on the motivation and usage behavior could then be evaluated (Agarwal and Karahanna 2000).

\section{Acknowledgement}

This paper presents research that was conducted in the context of the projects "StaySmart" and "ExTEND" funded by the German Federal Ministry of Education and Research (BMBF) (funding number project StaySmart:02L12A170, funding number project ExTEND: 02K14A172) and managed by the Project Management Agency Karlsruhe (PTKA). The responsibility for the content of this publication remains with the authors. 


\section{References}

Agarwal, R., and Karahanna, E. 200o. "Time Flies When You're Having Fun: Cognitive Absorption and Beliefs About Information Technology Usage," MIS Quarterly (24:4), pp. 665-694.

Aizaki, H. 2012. "Basic functions for supporting an implementation of choice experiments in R," Journal of statistical software (50), pp. 1-24.

Aizaki, H., and Nishimura, K. 2008. "Design and analysis of choice experiments using R: A brief introduction," Agricultural Information Research (17:2), pp. 86-94.

Alavi, M., and Leidner, D. E. 2001. "Research commentary: Technology-mediated learning-A call for greater depth and breadth of research," Information Systems Research (12:1), pp. 1-10.

Alcivar, I., and Abad, A. G. 2016. "Design and evaluation of a gamified system for ERP training," Computers in Human Behavior (58), pp. 109-118.

Amabile, T. M., Hill, K. G., Hennessey, B. A., and Tighe, E. M. 1994. "The Work Preference Inventory: Assessing intrinsic and extrinsic motivational orientations," Journal of Personality and Social Psychology (66:5), p. 950.

Attali, Y., and Areli-Attali, M. 2015. "Gamification in assessment: Do points affect test performance," Computers \& Education (83), pp. 57-63.

Barryl, H., Darryl, C., and Moore, A. 2014. "An Investigation of Gamification Typologies for Enhancing Learner Motivation," International Conference on Interactive Technologies and Games.

Baumgartner, B., and Steiner, W. J. 2007. "Are consumers heterogeneous in their preferences for odd and even prices? Findings from a choice-based conjoint study," International Journal of Research in Marketing (24:4), pp. 312-323.

Bedwell, W. L., Pavlas, D., Heyne, K., Lazzara, E. H., and Salas, E. 2012. "Toward a Taxonomy Linking Game Attributes to Learning: An Empirical Study," Simulation \& Gaming (43:6), pp. 729-760.

Bjork, S., and Holopainen, J. 2004. "Patterns in game design (game development series).

Boticki, I., Baksa, J., Seow, P., and Looi, C.-K. 2015. "Usage of a mobile social learning platform with virtual badges in primary school," Computers \& Education (86), pp. 120-136.

Bui, A., and Veit, D. 2015. "The Effects of Gamification on Driver Behavior: An Example from a Free Float Carsharing Service," Twenty-Third European Conference on Information Systems (ECIS), pp. 1-14.

Bunchball, I. 2010. "Gamification 101: An Introduction to the Use of Game Dynamics to Influence Behavior," (White Paper). Bunchball Inc..

Burgers, C., Eden, A., van Engelenburg, M. D., and Buningh, S. 2015. "How feedback boosts motivation in play in a brain-training game," Computers in Human Behavior (48), pp. 94-103.

Burke, M., and Hiltbrand, T. 2011. "How Gamification Will Change Business Intelligence," Business Intelligence Journal (16:2).

Christy, K. R., and Fox, J. 2014. "Leaderboards in a virtual classroom: A test of stereotype threat and social comparison explanations for women's math performance," Computers \& Education (78), pp. 66-77.

Cohen, S. H. 2003. "Maximum Difference Scaling: Improved Measures of Importance and Preferences for Segmentation," Sawtooth Research Paper Series, pp. 1-17.

da Rocha Seixas, L., Gomes, A. S., and de Melo Filho, Ivanildo José. 2016. "Effectiveness of gamification in the engagement of students," Computers in Human Behavior (58), pp. 48-63.

Davis, K., and Singh, S. 2015. "Digital badges in afterschool learning: Documenting the perspectives and experiences of students and educators," Computers \& Education (88), pp. 72-83.

de-Marcos, L., Domínguez, A., Saenz-de-Navarrete, J., and Páges, C. 2014. "An empirical study of comparing gamification and social networking on e-learning," Computers \& Education (75), pp. 82-91.

Demetrovics, Z., Urbán, R., Nagygyörgy, K., Farkas, J., Zilahy, D., Mervó, B., Reindl, A., Ágoston, C., Kertész, A., and Harmath, E. 2011. "Why do you play? The development of the motives for online gaming questionnaire (MOGQ)," Behavior research methods (43:3), pp. 814-825.

Denny, P. 2013. "The effect of virtual achievements on student engagement," Proceedings of the SIGCHI Conference on Human Factors in Computing Systems, pp. 763-772.

Deterding, S., Sicart, M., Nacke, L., O'Hara, K., and Dixon, D. 2011. "Gamification: Using Game Design Elements in Non-Gaming Contexts," Human Factors in Computing Systems, pp. 2425-2428.

Domínguez, A., Saenz-de-Navarrete, J., de-Marcos, L., Fernández-Sanz, L., Páges, C., and MartínezHerráiz, J.-J. 2013. "Gamifying learning experiences: Practical implications and outcomes," Computers \& Education (63), pp. 380-392. 
Eggers, F., and Sattler, H. 2009. "Hybrid individualized two-level choice-based conjoint (HIT-CBC): A new method for measuring preference structures with many attribute levels," International Journal of Research in Marketing (26:2), pp. 108-118.

Faghihi, U., Brautigam, A., Jorgenson, K., Martin, D., Brown, A., Measures, E., and Maldonado-Bouchard, S. 2014. "How Gamification Applies for Educational Purpose Specially with College Algebra," Procedia Computer Science (41), pp. 182-187.

Fernandes, J., Duarte, D., Ribeiro, C., Farinha, C., Madeiras Pereira, J., and Mira da Silva, M. 2012. "iThink: A game-based approach towards improving collaboration and participation in requirement elicitation," Procedia Computer Science (15), pp. 66-77.

Filsecker, M., and Hickey, D. T. 2014. "A multilevel analysis of the effects of external rewards on elementary students' motivation, engagement and learning in an educational game," Computers \& Education (75), pp. 136-148.

Fleming, N. 2014. Gamification: Is it game over? http://www.bbc.com/future/story/20121204-cangaming-transform-your-life. Accessed 25 April 2017.

Fogel, G. 2015. Will 80\% of gamification projects fail? Giving credit to Gartner's 2012 gamification forecast. http://www.gameffective.com/gamification-basics/will-80-of-gamification-projects-fail/. Accessed 25 April 2017.

Gnauk, B., Dannecker, L., and Hahmann, M. 2012. "Leveraging gamification in demand dispatch systems," Proceedings of the 2012 Joint EDBT/ICDT Workshops, pp. 103-110.

Hair, J. F., Black, W. C., Babin, B. J., and Anderson, R. E. 2010. Multivariate Data Analysis. A Global Perspective, New Jersey: Pearson.

Hakulinen, L., and Auvinen, T. (eds.). 2014. The effect of gamification on students with different achievement goal orientations, IEEE.

Hamari, J. 2013. "Transforming homo economicus into homo ludens: A field experiment on gamification in a utilitarian peer-to-peer trading service," Electronic Commerce Research and Applications (12), pp. $236-245$.

Hamari, J., Koivisto, J., and Sarsa, H. 2014. "Does Gamification Work?: A Literature Review of Empirical Studies on Gamification,” Hawaii International Conference on System Science (HICSS).

Hanus, M. D., and Fox, J. 2015. "Assessing the effects of gamification in the classroom: A longitudinal study on intrinsic motivation, social comparison, satisfaction, effort and, academic performance," Computers \& Education (80), pp. 152-161.

Hew, K. F., Huang, B., Chu, K. W. S., and Chiu, D. K. W. 2016. "Engaging Asian students through game mechanics: Findings from two experiment studies," Computers \& Education (92), pp. 221-236.

Hunicke, R., LeBlanc, M., and Zubek, R. 2004. "MDA: A formal approach to game design and game research," Proceedings of the AAAI Workshop on Challenges in Game AI, (4:1).

Huotari, K., and Hamari, J. 2012. "Defining Gamification - A Service Marketing Perspective," Proceeding of the 16th International Academic MindTrek Conference, pp. 17-22.

Ibánez, M.-B., Di-Serio, Á., and Delgado-Kloos, C. 2014. "Gamification for Engaging Computer Science Students in Learning Activities: A Case Study," IEEE Transactions on Learning Technologies (7:3), pp. 291-300.

Leimeister, J. M., Huber, M., Bretschneider, U., and Krcmar, H. 2009. "Leveraging crowdsourcing: activation-supporting components for IT-based ideas competition," Journal of Management Information Systems (26:1), pp. 197-224.

Li, W., Grossman, T., and Fitzmaurice, G. 2012. "GamiCAD: a gamified tutorial system for first time autocad users," Proceedings of the 25th annual ACM symposium on User interface software and technology, pp. 103-112.

Liu, Y., Alexandrova, T., and Nakajima, T. 2011. "Gamifying intelligent environments," Proceedings of the 2011 international ACM workshop on Ubiquitous meta user interfaces, pp. 7-12.

Matzner, M., Hoffen, M. von, Heide, T., Plenter, F., and Chasin, F. 2015. "A Method for Measuring User Preferences in Information Systems Design Choices," Twenty-Third European Conference on Information Systems (ECIS).

McFadden, D. 1973. "Conditional logit analysis of qualitative choice behavior", pp. 105-142.

Passos, E. B., Medeiros, D. B., Neto, P. A. S., and Clua, E. W. G. 2011. "Turning Real-World Software Development into a Game," Proceedings of SBGames, pp. 260-269.

Perry, B. 2015. "Gamifying French Language Learning: a case study examining a quest-based, augmented reality mobile learning-tool," Procedia Computer Science (174), pp. 2308-2315. 
Santhanam, R., Liu, D., and Shen, Wei-Cheng, Milton. 2016. "Research Note-Gamification of TechnologyMediated Training: Not All Competitions are the Same," Information Systems Research (27:2), pp. $453-465$.

Schlagenhaufer, C., and Amberg, M. 2015. "A Descriptive Literature Review and Classification Framework for Gamification in Information Systems," European Conference on Information Systems (ECIS).

Schöbel, S., Söllner, M., and Leimeister, J. M. 2016. "The Agony of Choice - Analyzing User Preferences regarding Gamification Elements in Learning Management Systems," International Conference on Information Systems (ICIS), Dublin, Ireland.

Seaborn, K., and Fels, D. I. 2015. "Gamification in theory and action: A survey," International Journal of human-computer studies (74), pp. 14-31.

Shang, S. S. C., and Lin, K. Y. 2013. "An Understanding of the Impact of Gamification on Purchase Intentions," Proceedings of the Nineteenth Americas Conference on Information Systems, pp. 1-11.

Simoes, J., Díaz Redondo, R., and Fernández Vilas Ana. 2013. "A social gamification framework for K-6 learning platform," Computers in Human Behavior (29), pp. 345-353.

Sims, R. 2003. "Promises of interactivity: Aligning learner perceptions and expectations with strategies for flexible and online learning," Distance Education (24:1), pp. 87-103.

$\mathrm{Su}, \mathrm{C} . \mathrm{-H}$., and Cheng, C.-H. 2015. "A mobile gamification learning system for improving the learning motivation and achievements," Journal of Computer Assisted Learning (31:3), pp. 268-286.

Thiebes, S., Lins, S., and Basten, D. 2014. "Gamifying Information Systems: A Synthesis of Gamification Mechanics and Dynamics," European Conference on Information Systems (ECIS).

Urh, M., Vukovic, G., and Jereb, E. 2015. "The model for introduction of gamification into e-learning in higher education," Procedia-Social and Behavioral Sciences (197), pp. 388-397.

Venkatesh, V., and Morris, M. G. 2000. "Why don't men ever stop to ask for directions? Gender, social influence, and their role in technology acceptance and usage behavior," MIS Quarterly (24:1), pp. 115139.

Zusho, A., Pintrich, P. R., and Cortina, K. S. 2005. "Motives, goals, and adaptive patterns of performance in Asian American and Anglo American students," Learning and Individual Differences (15:2), pp. 141158. 